\title{
Malária em usuários de drogas de administração endovenosa associada à soropositividade para HIV*
}

\author{
Shin Shiang Lo**, José Carlos Rehder de Andrade**, Maria Lúcia Fadel Condino**, \\ Maria José Chinelatto P. Alves ${ }^{* *}$, Marinês Gonzales Semeghini***, Edvar da Costa Galvão***
}

\begin{abstract}
LO, S.S. et al. Malária em usuários de drogas de administração endovenosa associada à soropositividade para HIV. Rev. Saúde públ., S. Paulo, 25: 17-22, 1991. Infecções induzidas de malária têm sido verificadas nos últimos anos no Estado de São Paulo, Brasil concomitantemente com o aumento de casos importados procedentes da região endêmica do país. Destaca-se o registro de um caso em 1988 e onze casos em 1989 de malária induzida por Plasmodium vivax, em indivíduos residentes na cidade de Presidente Prudente, situada a oeste do Estado e considerada uma das "portas de entrada" de pessoas procedentes da Região Amazônica. Os pacientes afirmaram não terem se deslocado recentemente ou negaram deslocamentos para áreas com possibilidade de transmissão de malária. Todos fizeram uso de drogas injetáveis, participando de círculos de conhecidos afins e geralmente dividiam a mesma agulha e seringa no uso da cocaína. Foi detectado o doente de malária que transmitiu inicialmente a doença ao caso de 1988, e a um primeiro grupo de três indivíduos em 1989. Destes três casos, um transmitiu a doença a outro grupo de dois indivíduos em 1989. A partir destas primeiras infecções e do uso continuado das drogas injetáveis entre grupos, surgiram dois novos casos e houve reinfecção em dois indivíduos (um destes apresentou duas reinfecções). O exame para detecção de HIV foi positivo em cinco indivíduos, um apresentou resultado negativo e não foi realizado em outros três indivíduos. São analisadas as informações desses casos e discutida a importância de sua ocorrência no momento atual.
\end{abstract}

Descritores: Malária, epidemiologia. Plasmodium vivax. Abuso de substâncias. HIV, análise.

\section{Introdução}

O controle da malária no Estado de São Paulo foi alcançado em meados da década de 60 , com o desenvolvimento do Programa de Erradicação executado pela Superintendência de Controle de Endemias (SUCEN). A partir de então foram registradas infecções importadas de áreas endêmicas do Brasil, concomitantemente com reduzido número de casos de transmissão local ${ }^{19}$. De 1983 a 1987 ocorreu aumento do número de casos importados, procedentes principalmente dos Estados de Rondônia, Mato Grosso e Pará ${ }^{14}$. A vigilância epidemiológica da doença foi então intensificada, a fim de evitar a reintrodução da endemia, muito embora focos importantes de transmissão tenhamse instalado em algumas áreas do Estado ${ }^{1}$.

Nesse período foram notificados 23 casos de malária induzida que podem ser distribuídos em

* Trabalho apresentado no XXVI Congresso da Sociedade Brasileira de Medicina Tropical, Natal, RN, 1990.

** Superintendência de Controle de Endemias (SUCEN) Rua Paula Souza, 166 - 01027 - São Paulo, SP Brasil.

*** Sistema Unificado e Descentralizado de Saúde - SP SUDS-SP 48 de Presidente Prudente - Presidente Prudente, SP - Brasil. três categorias, de acordo com o mecanismo de transmissão, segundo Bruce-Chwatt ${ }^{6}$. Assim, 20 casos foram devidos a prática transfusional, destacando-se 6 deles, no ano de 1984, em um serviço de hemoterapia na Região Metropolitana de São Paulo $^{2}$. Dois casos foram classificados como transmissão congênita e um por "agulha" acidental em usuário de drogas injetáveis. Vale assinalar que 3 casos não foram incluídos, uma vez que a transmissão esteve associada a mecanismo excepcional ( 1 caso por malarioterapia e 2 casos por acidente de trabalho). Proporcionalmente ao número de casos de malária importada, os classificados como induzidos são ínfimos. No ano de 1988, dos 2.499 casos notificados, $2.273(90,96 \%)$ foram importados e apenas $2(0,08 \%)$ induzidos ${ }^{15}$. Um destes indicava a introdução dos parasitas por "agulha" acidental durante o uso de drogas injetáveis.

O aparecimento de malária devido ao uso de drogas injetáveis teve a sua primeira epidemia descrita no Egito, por Biggam, em 1929, numa série de dez casos de malária falciparum em usuários de heroina e transmitidos por seringas ou agulhas. Outros episódios foram descritos nas décadas seguintes: Most (1940) coletou e analisou 86 casos com óbitos de malária falciparum em Nova York, durante os útlimos anos da década de 30 , e em 1948 Chung descreveu situação semelhante em 
Peiping - China (cf. Bruce-Chwatt ${ }^{6}$ ).

A partir do final da década de 60 , com o retorno de mais de um milhão de soldados americanos do sudeste asiático, aumentou o potencial de reservatórios de parasitas maláricos que, juntamente com a expanção do uso de drogas psicotrópicas, contribuiu para o reaparecimento da malária induzida acidentalmente em alguns países, especialmente nos Estados Unidos da América 4,5,6,8,9,13.

Infecções associadas ao uso de drogas estão centradas na utilização de equipamentos não estéreis (como agulhas, seringas, colheres, copos e outros), na preparação e na administração de drogas por injeção. A prática de compartilhá-los entre os usuários permite a disseminação de determinadas viroses sangüíneas. Duas destas práticas particularmente favorecem esta disseminação. Primeiro, a possibilidade de mistura da cocaína ou heroína dentro da seringa com o sangue do usuário. Isto resulta em contaminação do equipamento com o sangue, que é então passado para o próximo individuo. Segundo, a prática de lavar o equipamento em um copo ou recipiente com água, comum ao uso de todos, que rapidamente torna-se contaminado com sangue ${ }^{3}$.

A mais conhecida doença viral disseminada por sangue associada ao uso de drogas injetáveis, é a hepatite por vírus B. Recentemente, outra doença viral transmissivel, a AIDS ou o Vírus da Imunodeficiência Humana (HIV), tem-se espalhado entre os usuários de drogas ${ }^{3,10,12}$.

Na cidade de Presidente Prudente, pela Rodovia Raposo Tavares, escoa toda produção agropecuária de Estados como Mato Grosso e Mato Grosso do Sul e faz-se todo transporte de cargas para parte da Região Amazônica, área endêmica de malária. Este fluxo possibilita um registro importante de casos de malária importada na Região de Presidente Prudente. Informações da vigilância epidemiológica do SUDS-R-48* de Presidente Prudente apontam para um aumento do número de casos de AIDS e de portadores assintomáticos de HIV, na cidade, no decorrer de 1989.

A concomitância de malária e AIDS em usuários de drogas injetáveis é descrita no presente trabalho, em que a primeira apareceu como doença principal e que levou os doentes a procurarem os serviços médicos, sendo encaminhados à SUCEN-Regional de Presidente Prudente, ou a virem diretamente a essa instituição após a divulgação entre eles da confirmação da malária.

Informações do SUDS-R 48, Presidente Prudente, não publicadas.

\section{Material e Método}

A cidade de Presidente Prudente localiza-se a 565 Km da Capital, na região oeste do Estado de São Paulo, e é a principal cidade da $10^{\underline{2}}$ Região Administrativa. Possui uma população estimada de 161 mil habitantes e uma taxa de urbanização de $94,74 \%{ }^{18}$.

Foram estudados 12 casos de malária induzida, registrados na SUCEN Regional de Presidente Prudente, sendo 1 deles em agosto de 1988, e 11 em 1989, nos meses entre junho e novembro.

Todos os pacientes foram examinados pela técnica de gota espessa para o diagnóstico de malária, sendo a seguir preenchida ficha de investigação epidemiológica de acordo com modelo utilizado pela SUCEN. Em 6 pacientes foi possivel a realização do teste de MacElisa para HIV no Laboratório Regional de Presidente Prudente e quando positivo encaminhado ao Laboratório do Hospital das Clínicas da cidade de Marília, para os exames confirmatórios de Western-Blot e Reação de Imunofluorescência Indireta. A classificação da infeç̧ão pelo HIV e a complementação da ficha de investigação epidemiológica da AIDS seguiram critérios normatizados pelo Centro de Vigilância Epidemiológica do SUDS-SP e preenchidas pelo Centro de Saúde I (CS-I) de Presidente Prudente.

\section{Resultados e Discussão}

O exame hemoscópico para malária indicou, em todos os pacientes, infecção por Plasmodium vivax, espécie responsável pela prevalência de $70 \%$ observada nos casos importados diagnosticados pela SUCEN ${ }^{15}$.

O primeiro caso registrado foi notificado à SUCEN por suspeita de uma médica do Hospital São Sebastião de Presidente Prudente, após 6 dias de internação do paciente. O mesmo foi examinado e iniciou o tratamento em 4/8/88. Na história, referiu-se o uso de droga injetável em grupo, cinco dias antes do início dos sintomas, e neste encontrava-se uma pessoa que fazia freqüentes viagens a Mato Grosso (MT) e tivera malária várias vezes com diagnóstico fornecido pela Superintendência de Campanhas de Saúde Pública (SUCAM).

Em $1 / 6 / 89$, foi registrado novo caso de malária induzida por droga injetável. Esta notificação foi feita pelo Instituto Adolfo Lutz, durante a realização de um hemograma, por solicitação do Centro de Saúde I de Presidente Prudente, no dia 30/5/89. Na investigação, o paciente referiu o uso de droga injetável com 5 amigos, um dos quais foi o caso importado de MT, que iniciou a epidemia e outros dois que posteriormente apareceram com sintomas de malária. Entre esses dois, um já apre- 
sentava soropositividade para HIV desde 1987 , fato que determinou a pesquisa sorológica nos demais pacientes. $O$ outro iniciou uma cadeia de transmissão, na qual ele próprio foi infectado por $P$. vivax mais duas vezes, assim como o primeiro caso do ano deu origem a outra cadeia de transmissão e também se infectou duas vezes.

A análise das investigações epidemiológicas mostrou que nenhum dos pacientes fez doação ou recebeu transfusão de sangue nos 6 meses anteriores ao diagnóstico, bem como não haviam tido malária anteriormente, com excessão do introdutor da infecção no grupo. Todos os demais negaram deslocamentos para áreas com possibilidade de transmissão tanto no Estado de São Paulo, como em outros Estados do Brasil.

Na Tabela 1 encontra-se um resumo dos principais aspectos clínico-epidemiológicos obtidos com os 12 pacientes detectados. Vale assinalar as reinfecções observadas em dois deles, tendo em vista a não ocorrência de recaídas em malária induzida.

Os pacientes eram do sexo masculino, jovens, idade média de 24 anos, alguns inseridos em setores do comércio e da construção civil. Ao se distribuir os casos por local de residência e/ou trabalho, notou-se uma proximidade geográfica entre eles, com localização em área periférica da cidade.
O tempo decorrido entre o aparecimento dos sintomas de malária e a notificação à SUCEN, responsável pelo diagnóstico microscópico da doença, variou de 3 a 25 dias, com média de 8 . Considerando-se que a data da notificação coincide com a da realização do exame hemoscópico e conseqüentemente da instituição da terapêutica específica, observou-se intervalos prolongados para a procura do diagnóstico, tendo em vista a importância epidemiológica do período de parasitemia circulante. No Estado de São Paulo, nos anos de 1985 e 1986, praticamente $50 \%$ dos pacientes estudados procuraram a SUCEN para diagnóstico em um período de 1 a 3 dias $^{20}$. A demora observada na procura do diagnóstico, principalmente após a detecção dos dois primeiros pacientes, pode refletir o receio dos mesmos em procurar assistência médica, bem como a inexpressiva divulgação da gravidade do problema entre as pessoas em situação de risco em adquirir a malária.

A obtenção do intervalo compreendido entre a data provável da inoculação dos parasitas e o início dos primeiros sintomas foi prejudicada, pois os indivíduos que se infectaram, admitiram que freqüentemente usavam cocaína e partilhavam seus equipamentos, o que dificultava a lembrança das datas exatas. O período provável pode ser esti-

Tabela 1. Aspectos clínico-epidemiológicos dos 12 pacientes do sexo masculino com malária induzida por uso de drogas injetáveis. Presidente Prudente-SP, 1988 e 1989.

\begin{tabular}{|c|c|c|c|c|c|c|c|c|c|c|c|c|}
\hline \multirow{2}{*}{$\begin{array}{l}\text { Paciente/ } \\
\text { Idade }\end{array}$} & \multirow{2}{*}{ Ocupaçáo } & \multirow{2}{*}{$\begin{array}{c}\text { Data } \\
\text { inicio } \\
\text { sintomas }\end{array}$} & \multirow{2}{*}{$\begin{array}{c}\text { Data } \\
\text { da } \\
\text { notificaçăo }\end{array}$} & \multirow{2}{*}{$\begin{array}{c}\text { ntervalo } \\
\text { (dias) }\end{array}$} & \multicolumn{8}{|c|}{ Sintomas } \\
\hline & & & & & Febre & $\begin{array}{l}\text { Dor de } \\
\text { cabeça }\end{array}$ & $\begin{array}{c}\text { Dor } \\
\text { abdom. }\end{array}$ & Mialgia & Calafrios & Vomito & Náusea & $\begin{array}{l}\text { Sudo- } \\
\text { rese }\end{array}$ \\
\hline $1 / 39$ & $\begin{array}{l}\text { Comer- } \\
\text { clante }\end{array}$ & $25 / 7 / 88$ & $4 / 8 / 88$ & 11 & $x$ & $x$ & & & $x$ & $x$ & & \\
\hline $2 / 18$ & Cobrador & $28 / 5 / 89$ & $1 / 6 / 89$ & 5 & $x$ & $x$ & $x$ & & & & & \\
\hline $3 / 24$ & Armador & $2 / 6 / 89$ & $26 / 6 / 89$ & 25 & $x$ & $x$ & & $x$ & $x$ & $x$ & & \\
\hline $4 / 29$ & $\begin{array}{l}\text { Repr. co- } \\
\text { mercial }\end{array}$ & $30 / 6 / 89$ & $4 / 7 / 89$ & 5 & $x$ & $x$ & $x$ & & & $x$ & & \\
\hline $5 / 22$ & $\begin{array}{l}\text { Servente } \\
\text { pedreiro }\end{array}$ & $5 / 7 / 89$ & $12 / 7 / 89$ & 8 & $x$ & $x$ & & $x$ & $x$ & & $x$ & \\
\hline $6 / 16$ & Menor & $5 / 7 / 89$ & $14 / 7 / 89$ & 10 & $x$ & $x$ & & $x$ & $x$ & & & \\
\hline $7 * / 24$ & Armador & $15 / 8 / 89$ & $17 / 8 / 89$ & 3 & $x$ & $x$ & & $x$ & $x$ & & & \\
\hline $8 / 33$ & $\begin{array}{l}\text { Oper. } \\
\text { máquinas }\end{array}$ & $21 / 8 / 89$ & $25 / 8 / 89$ & 5 & $x$ & $x$ & $x$ & & $x$ & & & \\
\hline $9 *-/ 24$ & Armador & 23/9/89 & $26 / 9 / 89$ & 4 & $x$ & & & & & $x$ & & \\
\hline $10 / 18$ & $\begin{array}{l}\text { Mecánico } \\
\text { autónomo }\end{array}$ & 23/9/89 & $27 / 9 / 89$ & 5 & $x$ & $x$ & & & $x$ & $x$ & & \\
\hline $11^{* * / 18}$ & $\begin{array}{l}\text { Presi - } \\
\text { diário }\end{array}$ & $22 / 10 / 89$ & $30 / 10 / 89$ & 9 & $x$ & $x$ & & $x$ & $x$ & & & $x$ \\
\hline $12 / 23$ & $\begin{array}{l}\text { Desem- } \\
\text { pregado }\end{array}$ & $19 / 11 / 89$ & $27 / 11 / 89$ & 9 & $x$ & $x$ & & $x$ & $x$ & & & $x$ \\
\hline
\end{tabular}

- Reinfecçáo do paciente 3.

** Reinfecçáo do paciente 2. 
mado no intervalo de 5 a 45 dias, semelhante ao encontrado na literatura 5 .

Dos pacientes, 7 deles procuraram atendimentos em serviços médicos anteriormente à notificação à SUCEN. A Santa Casa de Presidente Prudente foi procurada por 4, o Centro de Saúde por 2 e o Hospital São Sebastião por 1. Os 4 últimos doentes detectados dirigiram-se diretamente à SUCEN, fato indicativo de uma divulgação da ocorrência de malária entre eles.

Quanto aos sinais e sintomas relatados, chama a atenção: febre $(100,0 \%)$; dor de cabeça $(91,6 \%)$, calafrios $(75,0 \%)$ e mialgia $(50,0 \%)$. Os dois primeiros constavam da ficha de investigação, em espaço fechado, os demais sintomas eram obtidos no decorrer da investigação, e preenchidos em espaço aberto, podendo ter conduzido a um viés na coleta das informações.

A malária vivax respondeu ao tratamento instituído, que seguiu o esquema de cloroquina + primaquina, sendo que esta última droga não era necessária em se tratando de transmissão induzida, conforme o preconizado pela SUCEN ${ }^{16}$.

$A$ indução de malária por qualquer mecanismo de transmissão é particularmente alarmante, se for considerada a incidência da doença no Brasil. Em 1989, portaria do Ministério da Saúde disciplinou a coleta, o processamento e a transfusão do sangue total, componentes e derivados, dando ênfase às doenças infecciosas conhecidas por sua transmissão sangüínea. Em áreas não endêmicas para malária, como o Estado de São Paulo, onde são poucos os casos induzidos, notificados por trans- fusão sanguínea, a transmissão entre toxicômanos que se injetam drogas passa a se destacar. O mesmo ocorre com o HIV, onde essa categoria de transmissão foi proporcionalmente a mais importante nos dois últimos anos, representando $19,8 \%$ do total de casos acumulado no período de 1980 a julho de 1989 no Estado de São Paulo ${ }^{17}$.

Encontra-se na Tabela 2 a época da realização dos exames sorológicos para AIDS de 6 dos 9 pacientes com malária induzida, os exames realizados e a classificação da infecção pelo HIV. Observa-se que 3 destes casos possuíam soropositividade para HIV antes do aparecimento do caso de malária induzida, em junho de 1989, mostrando que mesmo conhecendo os riscos da AIDS, e que um dos mecanismos de transmissão é o uso de drogas injetáveis, não se reduziu ou não se adotou qualquer medida preventiva no uso destas pelos pacientes.

O paciente 6 , cujo teste de ELISA foi realizado seis dias após o diagnóstico de malária induzida, foi o único resultado negativo. Os outros 5 , com testes de ELISA positivos, foram submetidos a exames confirmatórios de Western-Blot, e/ou Imunofluorescência Indireta. Foram classificados no Grupo II - infecção assintomática, com ausência de sinais ou sintomas, de acordo com as Normas Técnicas do Ministério da Saúde ${ }^{11}$.

Vale assinalar que o paciente 4 foi o segundo portador de HIV detectado na cidade de Presidente Prudente, a partir de 1987. Sua história teve início com uma internação por pneumonia na Santa Casa local, e pelo fato de ser usuário de drogas injetáveis foi realizado o teste de ELISA, em abril de 1987.

Tabela 2. Exames realizados entre os casos de malária induzida para diagnóstico de AIDS e classificação da infecção pelo HIV - Presidente Prudente-SP, 1988-1989.

\begin{tabular}{|c|c|c|c|}
\hline $\begin{array}{l}\text { Paciente } \\
\quad N^{2}\end{array}$ & $\begin{array}{l}\text { Data do } \\
\text { exame }\end{array}$ & Exames realizados & $\begin{array}{l}\text { Classificaçāo da } \\
\text { infecção pelo HIV }\end{array}$ \\
\hline 2 & $16 / 11 / 89$ & $\begin{array}{l}\text { Elisa + } \\
\text { Imunofluorescência Indireta + }\end{array}$ & Grupo II \\
\hline 3 & $29 / 8 / 88$ & $\begin{array}{l}\text { Elisa + } \\
\text { Western-Blot + }\end{array}$ & Grupo II \\
\hline 4 & $\begin{array}{r}3 / 4 / 87 \\
24 / 7 / 89\end{array}$ & $\begin{array}{l}\text { Elisa + } \\
\text { Elisa + } \\
\text { Western-Blot + }\end{array}$ & Grupo II \\
\hline \multirow[t]{2}{*}{5} & $1 / 8 / 89$ & $\begin{array}{l}\text { Elisa + } \\
\text { Western-Blot Indeterminado }\end{array}$ & Grupo II \\
\hline & $20 / 9 / 89$ & Imunofluorescência Indireta + & \\
\hline 6 & $20 / 7 / 89$ & Elisa - & - \\
\hline 8 & $28 / 9 / 88$ & $\begin{array}{l}\text { Elisa + } \\
\text { Western-Blot + }\end{array}$ & Grupo II \\
\hline
\end{tabular}


Com o resultado positivo, foram realizados os exames confirmatórios e o seu acompanhamento clínico por um ano no ambulatório de Doenças Sexualmente Transmissíveis e AIDS. O mesmo sempre esteve assintomático e não houve trabalho preventivo com paciente a respeito dos cuidados que deveria ter ao compartilhar drogas com outros indivíduos. Assim, em julho de 1989, ao apresentar os sintomas de malária, a suspeita clínica era de nova pneumonia.

Na cidade de Presidente Prudente, apesar das campanhas educativas de prevenção iniciadas no município quando do aparecimento dos primeiros casos de AIDS, não se manteve em ritmo intensivo o desenvolvimento dessas atividades.

Estatísticas da Vigilância Epidemiológica do SUDS-48*, indicam um aumento do número de portadores de HIV e de casos de AIDS no período de 1987 a 1989. De fevereiro a dezembro de 1987 haviam sido registrados 2 portadores de $\mathrm{HIV}$ e 2 casos de AIDS, enquanto que de janeiro a dezembro de 1989 estes números eram de 44 portadores de HIV e de 15 casos de AIDS. Ressalta-se que a maior parte destes casos, segundo combinação de situação de risco, apresentaram os usuários de drogas $(41,5 \%)$ entre os fatores simples e os homo/ drogas $(4,2 \%)$, hetero/drogas $(1,1 \%)$, bi/drogas/ transfusão $(1,1 \%)$, bi/drogas $(2,1 \%)$, droga/ transfusão $(1,1 \%)$ entre os fatores múltiplos, totalizando $51,1 \%$ dos fatores causais da doença na cidade. Estas informações compreendem o período de fevereiro de 1987 a dezembro de 1989, dados acumulativos.

Comentando sobre a educação com fins preventivos, Haverkos ${ }^{10}$ refere que a maioria dos especialistas em AIDS prognosticam uma diminuição na cooperação dos usuários de drogas, os quais se preocuparão cada vez menos com a sua própria saúde ou a do próximo, ao contrário do que tem se verificado nos programas educativos dirigidos aos homens homossexuais. Tal fato, reforça a necessidade de , ao se identificar pessoas infectadas por HIV, conscientizá-las, a fim de que tenham a "opção de proteger seus companheiros sexuais ou com os quais compartilham agulhas e a seus futuros filhos"10.

Merece ainda ser ressaltado o aparecimento de reinfecçð̃es de malária em dois pacientes, ocasionados ou pela frequiência com que estes fizeram uso das drogas ou por uma possível ausência de resposta ao tratamento convencional da malária vivax.

* Informações da SUDS-R-48, Presidente Prudente, não publicadas.

\section{Conclusర్es}

- Um antigo usuário de droga injetável dissiminou Plasmodium vivax em um grupo de toxicômanos, possibilitando a concomitância entre malária e infecção pelo HIV.

- O aumento do uso de drogas injetáveis poderá possibilitar o aparecimento de um número maior de casos de malária induzida, simultaneamente à infecção por HIV, ou a concomitância desta com outras infecções.

LO, S.S. et al. [The association of malaria, HIV seropositivity and intravenous administration in drug users]. Rev. Saúde públ., S. Paulo, 25: 17-22, 1991. Cases of induced malaria have been notified in S. Paulo State, Brazil, in recent years. At the same time the number of cases imported from endemic regions of Brazil has been increasing. One case of induced malaria by Plasmodium vivax was registered in Presidente Prudente, located in the west of the State, in 1988 and a further eleven cases in 1989. This city is considered to be one of the main transit ports for people who come into the State from the Amazonian region. The patients declared that they had not been to any possible transmission area of malaria. All of them had, however, taken cocaine, sharing the same contaminated needle and syringe. Previously, one person with imported malaria was detected, who had transmitted the disease to the first case in 1988 and also to a further group of 3 people in 1989. One of these three latter cases then transmitted the disease to two other people. As the group of people continued to use the drug among themselve, 2 new cases arose. Afterwards, they re-infected themselves again (one of the was re-infected twice). The test for Humam Immunodeficiency Virus was positive for 5 individuals, of whom one had a negative result and 2 others did not undergo the test. This information is discussed within the present context.

Keywords: Malária, epidemiology. Plasmodium vivax. Substance abuse. HIV, analysis.

\section{Referências Bibliográficas}

1. ANDRADE, J. C. R. de et al. Foco de malária do Estado de Sāo Paulo, Brasil. Rev. Saúde públ., S. Paulo, 20: 323-6, 1986

2. BARATA, L. C. B. et al. Malária transfusional: descrição de 6 casos induzidos em doadores de sangue na Região Metropolitana de São Paulo. Rev. Soc. bras. Med. trop., 22(supl.): 211, 1989. [XXV Congresso da Sociedade Brasileira de Medicina Tropical, Florianópolis, 1989].

3. BRETTLE, R. P. et al. Special problems of injecting drugmisures. Brit. med. Bull., 44: 149-60,1988.

4. BROWN, J. D. et al. Fatal falciparum malaria among narcotic injectors. Amer. J. trop. Med. Hyg., 24: 729-33, 1975.

5. BRUCE-CHWATT, L. J. et al. Blood transfusion and tropical diasese. Trop. Dis. Bull., 69: 825-62, 1972. 
6. BRUCE-CHWATT, L.J . Transfusion malaria revisited. Trop.Dis, Bull, 79: 827-40, 1982.

7. BRASIL. Leis etc. Decreto $n^{2} 95721$ de 11 de fevereiro de 1988. Diário Oficial da União, Seção 1, Brasília, 12 fev, 1988. p. 2606.

8. DOVER, A.S. Malaria in a heroin user. J. Amer, med. Ass., 215: 1987, 1971.

9. FRIEDMANN, C. T. H. et al. A malaria epidemic among heroin users. Amer. J. trop. Med. Hyg., 22: 302-7, 1973.

10. HAVERKOS, H. W. Diagnostico y tratamiento del SIDA en los Estados Unidos. Bol. Ofic. sanil. Panamer., 106: 503-11, 1989.

11. MINISTERIO DA SAÚDE. Recomendaçăo para prevenção e controle da infecçāo pelo vírus HIV (SIDA. AIDS). Brasília, 1987. (Normas e Manuais Técnicos).

12. RODRIGUES, L. G. de M. \& CHEQUER, P. SIDA no Brasil, 1982 a 1988. Bol. Ofic. sanit. panamer., 105: 504-9, 1988.

13. ROSENBLATT, J. E. \& MARSH, V. H. Induced malaria in narcotic addicts. Lancet, 2: 189-90, 1971.

14. SECRETARIA DA SAÚDE. Superintendência de Controle de Endemias. Programa de Controle da Malária no Estado de São Paulo. Avaliaçāo. São Paulo, 1987. [Mimeografado].
15. SECRETARIA DA SAÚDE. Superintendência de Controle de Endemias. Programa de Controle da Malária no Estado de São Paulo. Avaliação. São Paulo, 1988. [Mimeografado].

16. SECRETARIA DA SAÚDE. Superintendência de Controle de Endemias. Malária: esquemas terapêuticos. São Paulo, 1987. [Mimeografado].

17. SECRETARIA DA SAÚDE. "AIDS" no Estado de São Paulo. Bol epidem., São Paulo, jul. 1989.

18. SECRETARIA DO PLANEJAMENTO. Sistema de Informações das Regiōes de Govemo. Hierarquia das regiōes e dos municlpios do Estado de São Paulo. São Paulo, 1987.

19. WANDERLEY, D. M. V. et al. Malária no Estado de São Paulo, 1980 a 1983. Rev. Saúde públ., S. Paulo, 19: 28-36, 1985.

20. WANDERLEY, D. M. V. et al. Malária no Estado de São Paulo: avaliação de aspectos da vigilância epidemiológica. Cad. Saúde públ., Rio de Janeiro, 5: 296-304, 1989.

Recebido para publicaçäo em 25/5/1990. Aprovado para publicação em S/11/1990. 